J. Dairy Sci. 98:5899-5904

http://dx.doi.org/10.3168/jds.2015-9442

(C) American Dairy Science Association ${ }^{\circledR}, 2015$.

\title{
Effect of essential oils of Syzygium aromaticum and Cinnamomum zeylanicum and their major components on biofilm production in Staphylococcus aureus strains isolated from milk of cows with mastitis
}

\author{
P. E. Budri, ${ }^{\dagger}$ N N. C. C. Silva, ${ }^{\star} \ddagger$ E. C. R. Bonsaglia, ${ }^{*}$ A. Fernandes Júnior, ${ }^{*}$ J. P. Araújo Júnior, ${ }^{*}$ J. T. Doyama,§ \\ J. L. Gonçalves,\# M. V. Santos,\# D. Fitzgerald-Hughes,† and V. L. M. Ralı*1 \\ *Department of Microbiology and Immunology, Instituto de Biociências, Universidade Estadual Paulista (UNESP), Botucatu, SP, \\ Brazil 18618-970 \\ †Department of Clinical Microbiology, Royal College of Surgeons in Ireland (RCSI), Beaumont Hospital, Dublin, Ireland 2 \\ ‡Department of Agroindustry, Food and Nutrition, Universidade de São Paulo (USP), Piracicaba, SP, Brazil 13418-900 \\ $\S$ Department of Chemistry e Biochemistry, Instituto de Biociências, UNESP, Botucatu, SP, Brazil 18618-970 \\ \#Department of Animal Science, School of Veterinary Medicine and Animal Science (USP), Pirassununga, SP, Brazil 113635-900
}

\begin{abstract}
Bovine mastitis is an inflammation of the mammary glands of cows and causes significant economic losses in dairy cattle. Staphylococcus aureus is one of the microorganisms most commonly isolated. Novel agents are required in agricultural industries to prevent the development of mastitis. The production of biofilm by Staph. aureus facilitates the adhesion of bacteria to solid surfaces and contributes to the transmission and maintenance of these bacteria. The effect of the essential oils of Syzygium aromaticum (clove; EOSA) and Cinnamomum zeylanicum (cinnamon; EOCZ) and their major components, eugenol and cinnamaldehyde, on Staph. aureus biofilm formation on different surfaces was investigated. The results showed a significant inhibition of biofilm production by EOSA on polystyrene and stainless steel surfaces (69.4 and $63.6 \%$, respectively). However, its major component, eugenol, was less effective on polystyrene and stainless steel ( 52.8 and $19.6 \%$, respectively). Both EOCZ and its major component, cinnamaldehyde, significantly reduced biofilm formation on polystyrene (74.7 and $69.6 \%$, respectively) and on stainless steel surfaces (45.3 and $44.9 \%$, respectively). These findings suggest that EOSA, EOCZ, and cinnamaldehyde may be considered for applications such as sanitization in the food industry.

Key words: mastitis, antibiofilm Staphylococcus aureus, Syzygium aromaticum, Cinnamomum zeylanicum
\end{abstract}

\section{INTRODUCTION}

Bovine mastitis is an inflammation of the mammary glands in dairy cattle, usually caused by bacteria. It

Received February 7, 2015.

Accepted May 20, 2015.

${ }^{1}$ Corresponding author: vlmores@ibb.unesp.br leads to significant economic losses due to reduced milk production, increased use of drugs and animal morbidity and mortality (Melchior et al., 2006). Staphylococcus aureus is one of the most important causative agents of clinical, subclinical, or chronic mastitis (Vasudevan et al., 2003).

Staphylococcus aureus can produce biofilms, complex polysaccharide- or protein-bound bacterial structures that facilitate adhesion and multiplication of bacteria on environmental surfaces and on animal tissues. Bacteria in biofilms are resistant to phagocytosis, antimicrobial agents, and disinfectants due to the low diffusion through the matrix and altered cellular metabolism (Donlan and Costerton, 2002). These protective features of Staph. aureus biofilms promote colonization of the mammary epithelium which precedes the establishment of a persistent infection (Lasa and Penadés, 2006).

Staphylococcus aureus polysaccharide production is mediated by the $i c a$ cluster (intercellular adhesin), which contains icaA, icaB, icaC, and icaD (McKenney et al., 1998). Co-expression of $i c a A$ and $i c a D$ results in phenotypic expression of capsular polysaccharide (Arciola et al., 2001). Another important gene involved in biofilm production in Staph. aureus is bap, which encodes biofilm-associated protein. Biofilm-associated protein promotes primary binding to surfaces and intercellular adhesion (Lasa and Penadés, 2006), but its prevalence is reported to be relatively low (Seo et al., 2008).

Due to the high prevalence of biofilm production among Staph. aureus in mastitis, increased investment in industrial equipment disinfection programs that target biofilms has been noted (Gibson et al., 1999). Essential oils (EO) have antimicrobial and antibiofilm activity against bacteria, parasites (Alexopoulos et al., 2011), fungi (Mari et al., 2003), and viruses (Bishop, 1995). More recently, EO of aromatic and medicinal 
plants have been tested for their activity against biofilms (Kwiecinski et al., 2009). The EO target different cellular mechanisms, such as inhibition of peptidoglycan synthesis (Ogunlana et al., 1987), modification of bacterial membrane hydrophobicity (Cox et al., 2000), and modulation of quorum sensing (Gao et al., 2003). Sanitizers based on natural products, such as EO with specific Staph. aureus antibiofilm activity, may have applications in the beef-processing industry for enhanced surface or carcass cleaning. The aim of our study was to evaluate the effect of the essential oil of clove (Syzygium aromaticum; EOSA), cinnamon (Cinnamomum zeylanicum; EOCZ), and their major compounds, eugenol and cinnamaldehyde, on biofilm formation on stainless steel and polystyrene by isolates of Staph. aureus recovered from the milk of cows with subclinical mastitis.

\section{MATERIALS AND METHODS}

\section{Samples and Bacterial Isolation}

A collection of 64 isolates of Staph. aureus, previously recovered from the milk of cows with subclinical mastitis, was tested. Presumptive identification was by Gram stain and further confirmation was made based on catalase, coagulase, and DNase production, as described by Koneman et al. (2008). Molecular confirmation was by PCR amplification of the species-specific staphylococcal nuclease gene (nuc) using primers and PCR conditions as outlined in Table 1.

\section{PCR to Detect Genes Linked to Biofilm Production}

The DNA extraction was performed using the Minispin kit (GE Healthcare, Little Chafont, Buckinghamshire, UK) according to the manufacturer's instructions. The PCR reactions were performed with each primer pair in a final volume of $25 \mu \mathrm{L}$ containing 2.5 $\mu \mathrm{L}$ of $10 \times$ PCR buffer, $2.0 \mathrm{~m} M$ magnesium chloride, $200 \mathrm{~m} M$ deoxynucleotides, $1 \mathrm{U}$ of Taq DNA polymerase (Fermentas, St. Leon Rot, Germany), 10 pmol of each primer, and $3 \mu \mathrm{L}$ of the DNA template. The primers used for detection of $i c a A$, icaD, and bap and their properties are listed in Table 1. The PCR conditions were those described in the references provided (Table 1) with reactions performed in a Gene Amp PCR System 9700 (Applied Biosystems, Carlsbad, CA). The PCR products were detected using 1.5\% agarose gel in Trisboric acid-EDTA buffer and developed with Sybr Green (Invitrogen, Grand Island, NY). Positive and negative controls for icaA and icaD were Staph. aureus ATCC 35983 and Staphylococcus epidermidis ATCC 12.228. For bap, a positive and sequenced strain was used.

\section{Extraction of EOSA and EOCZ and Chemical Analysis by GC-MS}

The EOSA and EOCZ were extracted from Syzygium aromaticum and Cinnamomum zeylanicum by drag steam distiller (model MA480, Marconi, Piracicaba, Brazil). Densities were calculated according to Fonseca and Librand (2008). The major compounds of the EOSA and EOCZ, eugenol and cinnamaldehyde, were sourced commercially (Sigma-Aldrich, St. Louis. MO).

Chemical characterization was determined by gas chromatography coupled to GC-MS (model QP5050A, Shimadzu, Kyoto, Japan) with the use of a CBP-5 capillary column with a $0.25-\mathrm{mm}$ internal diameter and $0.25-\mu \mathrm{m}$ film thickness. The chromatographic conditions were set according to the EO analyzed. Both EOSA and EOCZ were identified by matching their mass spectra to reference compounds in the National Institute of Standards and Technology mass spectra library (Gaithersburg, MD).

\section{Determination of the Minimum Inhibitory Concentration}

Susceptibility tests were performed in triplicate for EOSA, EOCZ, and their major components using the broth microdilution method and CLSI (2009) guidelines. Briefly, inocula of Staph. aureus were prepared to the density of $0.5 \mathrm{McFarland}$ using a densitometer (Densichek, BioMérieux, Durham, NC) in $0.85 \%$ saline solution. The inocula were further diluted to an approximate concentration of $10^{5} \mathrm{cfu} / \mathrm{mL}$ and incubated with test compounds at concentrations of $0.025,0.04$, $0.06,0.08,0.10,0.20,0.40$, and $0.80 \%$, in final volumes of $200 \mu \mathrm{L}$ of brain-heart infusion broth (Oxoid, Basingstoke, UK) supplemented with $0.5 \%$ Tween 80 . Positive growth controls and sterility controls were included.

Plates were incubated at $35^{\circ} \mathrm{C}$ for $24 \mathrm{~h}$, after which $50 \mu \mathrm{L}$ of $0.01 \%$ resazurin was added to each well. The MIC was recorded as the lowest concentration of EO or EO components at which no growth was observed, as indicated by a change of color from blue to pink (Coban, 2012).

\section{Production of Biofilm by Staph. aureus in the Presence and Absence of the EO and Their Major Compounds}

Isolates were cultured in tryptone soy broth (Oxoid), at $37^{\circ} \mathrm{C}$ for $24 \mathrm{~h}$, and diluted to approximately $10^{8} \mathrm{cfu} /$ $\mathrm{mL}$. Eugenol and cinnamaldehyde was added to $200 \mu \mathrm{L}$ of the tryptone soy broth dilution separately to a final concentration of $0.106 \mathrm{mg} / \mathrm{mL}$ (subinhibitory concen- 
Table 1. Oligonucleotides used in the detection of biofilm genes and confirmation of identification of Staphylococcus aureus strains isolated from milk of cows with subclinical mastitis

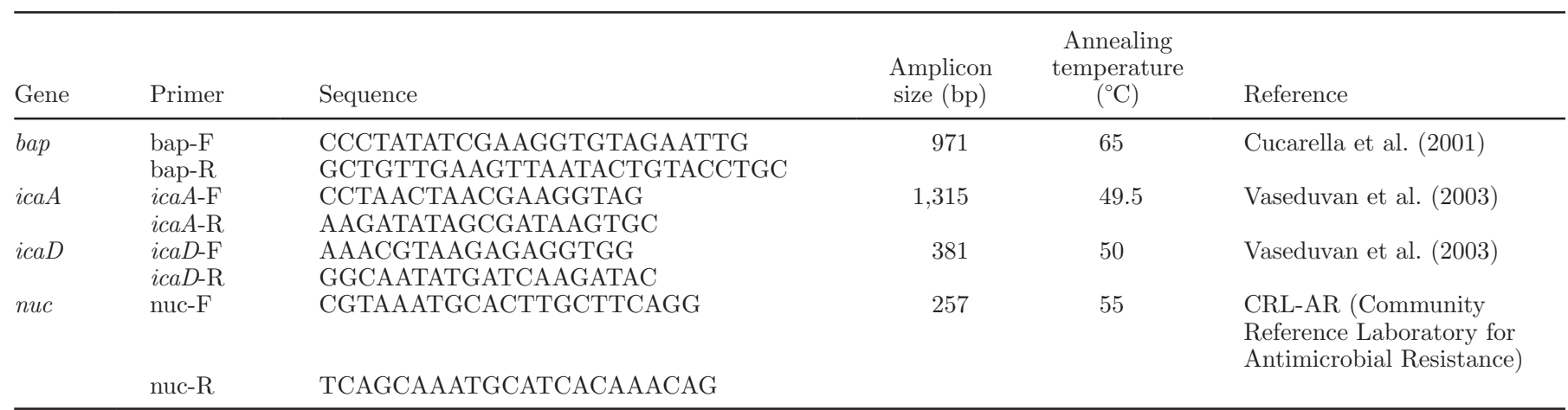

tration based on MIC determination). The experiment was carried out in triplicate using a 96-well microtiter plate. Control assays were prepared similarly, but $\mathrm{EO}$ and major components were replaced with sterile tryptone soy broth. Plates were incubated at $35^{\circ} \mathrm{C}$ for $48 \mathrm{~h}$ in a static incubator, washed 3 times with PBS ( $\mathrm{pH}$ 7.4), dried at room temperature, and stained with $1 \%$ gentian violet. After a further wash with distilled water, absorbance at $570 \mathrm{~nm}$ was measured using an ELISA plate reader (Multiskan EX, Thermo Scientific, Waltham, MA). Staphylococcus aureus ATCC 35983 was used as positive control (biofilm producer) and S. epidermidis ATCC 12228 as a negative control for biofilm production (Vasudevan et al., 2003).

\section{Effect of EO and Major Components on Biofilm Formation on Stainless Steel}

Sterile stainless steel coupons with a diameter of 1 $\mathrm{cm}$ were deposited at the bottom of a 24-well plate and Staph. aureus overnight cultures were diluted to $10^{8}$ $\mathrm{cfu} / \mathrm{mL} ; 300-\mu \mathrm{L}$ aliquots were then added to triplicate wells containing the coupons and incubated at $35^{\circ} \mathrm{C}$ for $48 \mathrm{~h}$ in the absence and presence of each $\mathrm{EO}$ and their major components $(0.106 \mathrm{mg} / \mathrm{mL})$. The coupons were transferred to a new plate, washed 3 times with PBS (pH 7.4), and stained with $1 \%$ crystal violet for $15 \mathrm{~min}$ and washed a further 3 times. The biofilm was resuspended in $300 \mu \mathrm{L}$ of glacial acetic acid for $15 \mathrm{~min}$ and $200 \mu \mathrm{L}$ was transferred to a microplate and the absorbance measured at $570 \mathrm{~nm}$.

\section{Statistical Analysis}

To compare the effect on biofilm production in the absence and presence of $\mathrm{EO}$ and major components, ANOVA was conducted in a randomized design followed by Tukey test means. A $P$-value $<0.05$ was considered significant.

\section{RESULTS}

\section{Genotypic Analysis for the Presence of ica $A$, ica $D$, and bap}

From 64 isolates of Staph. aureus, 26 (40.6\%) were positive for all 3 biofilm genes investigated (icaA, icaD, and bap). The icaA gene alone was detected in $85.9 \%$ and $i c a D$ in $84.3 \%$ of isolates. Representative amplicons from bap, icaA, and $i c a D$ PCR were partially sequenced and confirmed in GenBank (GenBank accession numbers AY220730.1, CP006838.1, and JN226155.1, respectively).

\section{Chemical Analysis by GC-MS}

Details of the physicochemical characteristics of EOSA, EOCZ, eugenol, and cinnamaldehyde are shown in Table 2. The major component of EOSA was eugenol (90.21\%) and of EOCZ was cinnamaldehyde (86.59\%). The MIC values toward Staph. aureus isolates are also shown.

\section{MIC of EO and Major Compounds}

The MIC of eugenol and EOSA were 0.392 and 0.237 $\mathrm{mg} / \mathrm{mL}$, respectively. The EOCZ and cinnamaldehyde showed MIC of 0.243 and $0.199 \mathrm{mg} / \mathrm{mL}$, respectively.

\section{Effect of EO and Major Components on Biofilm Formation on Polystyrene and Stainless Steel Coupons}

The effect of EO and their major components on Staph. aureus biofilm formation on polystyrene and stainless steel surfaces are summarized in Table 3. Optical density values (at $570 \mathrm{~nm}$ ) obtained in the presence of natural compounds are shown in addition to the percentage remaining following exposure to the 
Table 2. Physicochemical analyses and minimum inhibitory concentration (MIC90\%) values toward Staphylococcus aureus isolates of clove essential oil, cinnamon essential oil, and their major compounds

\begin{tabular}{|c|c|c|c|}
\hline Species or compound & $\begin{array}{l}\text { Density } \\
(\mathrm{mg} / \mathrm{mL})\end{array}$ & $\begin{array}{c}\mathrm{MIC} \mathrm{90 \%}{ }^{1} \\
(\mathrm{mg} / \mathrm{mL})\end{array}$ & Composition (\%) \\
\hline Syzygium aromaticum & 1,060 & $\begin{array}{c}0.392 \\
(0.187)\end{array}$ & $\begin{array}{l}\text { Eugenol }(90.2 \%) \text {, } \\
\text { eugenol acetate }(6.5 \%) \text {, } \\
\beta \text {-caryophyllene }(1.3 \%) \text {, others }(1.9 \%)\end{array}$ \\
\hline Eugenol & 1,050 & $\begin{array}{l}0.237 \\
(0.211)\end{array}$ & Eugenol $(100 \%)$ \\
\hline Cinnamomum zeylanicum & 1,075 & $\begin{array}{c}0.243 \\
(0.211)\end{array}$ & $\begin{array}{l}\text { Cinnamaldehyde }(86.5 \%) \text {, benzaldehyde } \\
(4.2 \%) \text {, cineole }(1.7 \%) \text {, cinnamic acid } \\
(1.5 \%) \text {, eugenol }(0.1 \%) \text {, others }(5.42 \%)\end{array}$ \\
\hline cinnamaldehyde & 1,080 & $\begin{array}{c}0.199 \\
(0.106)\end{array}$ & Cinnamaldehyde $(100 \%)$ \\
\hline
\end{tabular}

${ }^{1} \mathrm{MIC}$ values (CI in parentheses) shown are the mean found for 26 Staph. aureus isolates.

natural compounds. The values obtained in the absence of EO or their major components were 0.415 (100\%) for polystyrene and $1.07(100 \%)$ in stainless steel.

Significant differences in biofilm production were noted between isolates grown in the absence and presence of EO or major components. A statistically significant reduction in biofilm formation was observed in the presence of EOSA and EOCZ $(P<0.01)$ on both polystyrene as stainless steel. Cinnamaldehyde and eugenol resulted in a statistically significant reduction in biofilm formation on polystyrene $(P<0.001)$, but on stainless steel a significant reduction in biofilm was seen for cinnamaldehyde $(P<0.01)$ and not eugenol.

Comparing the antibiofilm activity of each EO to its major component, similar antibiofilm activity was found for EOCZ and its major component, cinnamaldehyde, on both test surfaces. However, EOSA was more effective in reducing biofilm on polystyrene and stainless steel than was eugenol.

\section{DISCUSSION}

Among the 64 isolates, $40.6 \%$ carried icaA, icaD, and bap simultaneously. IcaD and icaA are reported more frequently in Staph. aureus isolates from cows with mastitis than bap (Atshan and Shamsudin, 2011). How- ever, the prevalence of bap among Staph. aureus isolates from bovine mastitis found here are significantly higher than previously reported by others (Vautor et al., 2008; Seixas et al., 2014). Cucarella et al. (2001) found 5\% positivity for bap in 350 strains tested and Vautor et al. (2008) could not detect bap among 262 Staph. aureus associated with different diseases and recovered from humans and animals. The relatively high bap carriage rate found here, as compared with other studies, suggests that bap acquisition by Staph. aureus may be a recent event or that its transmission by horizontal transfer remains limited despite its presence on a mobile transposon-like element, SaPIbov2. Transmission events involving this gene may be on the increase.

The chemical composition of EO extracted from Syzygium aromaticum and Cinnamomum zeylanicum were similar to that found by other authors. The main components of the EOSA were eugenol (90.21\%) and eugenol acetate (6.5\%). Bauer et al. (2001) observed the same components at concentrations of 75 to $85 \%$ and 8 to $15 \%$, respectively. The components of EOCZ, cinnamaldehyde (86.5\%) and benzaldehyde (4.2\%), were similar to those reported by Unlu et al. (2010;68.9 and $9.9 \%$, respectively). However, unlike the study of Unlu et al. (2010), small quantities of cinnamaldehyde acetate $(7.4 \%)$ were found in the present study. As sug-

Table 3. Staphylococcus aureus biofilm formation on polystyrene and stainless steel in the presence of clove essential oil (EOSA), cinnamon essential oil (EOCZ), and its major components

\begin{tabular}{lcccc}
\hline & & & \multicolumn{2}{c}{$P$-value } \\
\cline { 5 - 5 } Item & $\begin{array}{c}\text { Polystyrene } \text { OD }_{570}{ }^{1} \\
(\% \text { reduction })\end{array}$ & $\begin{array}{c}\text { Stainless steel OD } \\
(\% \text { reduction })\end{array}$ & Polystyrene & Stainless steel \\
\hline Control & $0.415 \pm 0.075(0)^{\mathrm{a}}$ & $1.07 \pm 0.222(0)^{\mathrm{ab}}$ & - & \\
EOSA & $0.127 \pm 0.047(69.4)^{\mathrm{b}}$ & $0.390 \pm 0.080(63.5)^{\mathrm{c}}$ & $<0.01$ & $<0.01$ \\
Eugenol & $0.196 \pm 0.067(52.8)^{\mathrm{c}}$ & $0.860 \pm 0.220(19.2)^{\mathrm{b}}$ & $<0.01$ & $>0.05$ \\
EOCZ & $0.105 \pm 0.040(74.7)^{\mathrm{b}}$ & $0.585 \pm 0.158(45.3)^{\mathrm{c}}$ & $<0.01$ & $<0.01$ \\
Cinnamaldehyde & $0.126 \pm 0.078(69.4)^{\mathrm{b}}$ & $0.589 \pm 0.100(44.9)^{\mathrm{c}}$ & $<0.01$ & $<0.01$ \\
\hline
\end{tabular}

${ }^{\mathrm{a}-\mathrm{C}}$ Values followed by the same letter in the column do not differ.

${ }^{1}$ Optical density at $570 \mathrm{~nm}$. 
gested by Burt (2004), it is possible that intraspecies variations in composition may be due to genetic variation, seasonality, geographic location, harvest time, and plant parts used in the preparation of oil.

The MIC values of EO and their major components toward planktonic cells of Staph. aureus were similar to those observed in previous studies (Unlu et al., 2010). From the values of MIC, a sub-MIC dose of $0.106 \mathrm{mg} /$ $\mathrm{mL}$ of EO and their components were used for biofilm studies. Furthermore, no corrosion of polystyrene plate surface, attributed to effects of EO (which may have resulted in false-positives due to dye uptake), was observed at this concentration.

Biofilm formation on polystyrene surfaces decreased by 69.4 and $74 \%$ in the presence of EOSA and EOCZ, respectively. Cinnamaldehyde also reduced biofilm on polystyrene by $69.6 \%$ and eugenol treatment resulted in a $52.8 \%$ reduction. The greatest reduction in biofilm formation on stainless steel was found for EOSA (63.5\%), followed by EOSZ (45.3) and cinnamaldehyde (44.9\%). Eugenol had the least effect on biofilm on this surface $(19.6 \%)$.

Our finding that the eugenol component of EOSA did not significantly contribute to the antibiofilm activity of EOSA suggests that other component within the oil may be responsible. According to Bassolé et al. (2010), the antibacterial activity of an EO is mainly due to its major components, but antimicrobial synergy may result from interactions with other minor components. Conversely, based on the similarity in biofilm disruption on 2 surface types, for EOCZ and its major component, cinnamaldehyde, we suggest the efficiency of EOCZ is closely linked to its major component.

Several studies have investigated antibacterial activity of natural compounds and several mechanisms have been suggested. According to Shen et al. (2015), bacterial morphologies of Escherichia coli and Staph. aureus, besides their cell membrane integrity and permeability, are damaged when these cells were exposed to cinnamaldehyde MIC. These alterations are correlated with the ability of hydrocarbons to interact in hydrophobic structures, such as bacterial membranes. The principal antibacterial mechanism of eugenol is due to its increasing nonspecific permeability of cytoplasmic membrane resulting in the disruption of the membrane, and the suppression of enzyme action caused by hydroxyl group on eugenol bond to proteins (Li et al., 2015).

The EOCZ and cinnamaldehyde has significant antimicrobial properties covering a broad spectrum of microorganisms. Kim et al. (2015) demonstrated inhibited the production of Pseudomonas quinolone signal, the swarming motility, and the biofilm formation using those compounds in Pseudomonas aeruginosa. Kim et al. (2015) also suggests that biofilm inhibition by cin- namaldehyde was partially caused by the downregulation of quorum-sensing systems and scanning electron microscopy analysis suggested that cinnamon oil, cinnamaldehyde, and eugenol reduce fimbriae production.

Other EO and their major components also exhibit inhibition of initial biofilm formation. Carvacrol, one of the main antibacterial components of oregano oil and other EO, was reported to inhibit biofilms of Staph. aureus and Salmonella typhimurium in the initial growth phase and prevented the formation of mature biofilms (Knowles et al., 2005). Saviuc et al. (2015) explain the antibiofilm characteristic of carvacrol due to the fact it facilitates cellular permeability by coatings interacting, thus favoring the antimicrobial activity of terpenoids. Nostro et al. (2007) reported low biofilm formation by various strains of Staph. aureus and S. epidermidis in the presence of sublethal concentrations of EO of oregano, carvacrol, and thymol. Similar results were obtained for strains of Salmonella typhimurium in the presence of sublethal concentrations of EO of thyme, oregano, and carvacrol (Soni et al., 2013). The hydrophobic nature of these compounds is responsible for interaction with the lipid bilayer of cytoplasmic membranes causing disintegration and leakage of cellular material such as ions, ATP, and nucleic acid (Nostro et al., 2007).

To elucidate the mechanism of action of $\mathrm{EO}$ or major components in a biofilm environment a complex approach is used, considering molecular properties, interactions with environmental factors, and microorganismtargeting sites. Although complex, some antimicrobial action mechanisms are widely documented, such as permeabilization of cell membranes, plasma membrane depolarization, impairment of lipid polymorphism, interaction with the outer membrane proteins in gramnegative bacteria, affecting the respiratory processes, coagulating the cytoplasmic material, and depletion of intracellular ATP (Saviuc et al., 2015).

The present study observed strong antibiofilm activity for EOSA, EOCZ, and cinnamaldehyde against Staph. aureus recovered from cases of subclinical bovine mastitis. However, some studies have shown that low concentrations of EO, such as tea tree oil and cinnamaldehyde, can increase bacterial metabolic activity in relation to biofilm production due to environmental stress in Staph. aureus and Pseudomonas aeruginosa, respectively (Kwiecinski et al., 2009).

\section{CONCLUSIONS}

Despite the low extraction yield of EOSA, EOCZ, and cinnamaldehyde from Syzygium aromaticum and Cinnamomum zeylanicum, the strong antibiofilm activity reported here on stainless steel and polystyrene, at low concentrations of these substances, indicates their 
potential for development. A specific application could be as an alternative sanitizing spray for surface cleaning in the food processing industry.

\section{ACKNOWLEDGMENTS}

The authors thank Coordenação de Aperfeiçoamento de Pessoal de Nível Superior (CAPES) and the Conselho Nacional de Pesquisa (CNPq, Brasilia, Brazil), for financial support.

\section{REFERENCES}

Alexopoulos, A., A. C. Kimbaris, S. Plessas, I. Mantzourani, I. Theodoridou, E. Stavropoulou, M. G. Polissiou, and E. Bezirtzoglou. 2011. Antibacterial activities of essential oils from eight Greek aromatic plants against clinical isolates of Staphylococcus aureus. Anaerobe 17:399-402.

Arciola, C. R., L. Baldassarri, and L. Montanaro. 2001. Presence of $i c a A$ and $i c a D$ genes and slime production in a collection of staphylococcal strains from catheter-associated infections. J. Clin. Microbiol. 39:2151-2156.

Atshan, S. S., and M. N. Shamsudin. 2011. Evaluation of phenotypic and genotypic detection methods for biofilm-forming methicillinsensitive and methicillin-resistant Staphylococcus aureus clinical isolates. Ann. Microbiol. 61:825-831.

Bassolé, I. H. M., A. Lamien-Meda, B. Bayala, S. Tirogo, C. Franz, J. Novak, R. C. Nebié, and M. H. Dicko. 2010. Composition and antimicrobial activities of Lippia multiflora Moldenke, Mentha x piperita L. and Ocimum basilicum L. essential oils and their major monoterpene alcohols alone and in combination. Molecules 15:7825-7839

Bauer, K., D. Garbe, and H. Surburg. 2001. Common Fragrance and Flavor Materials: Preparation, Properties and Uses. 4th ed. WileyVCH, Weinheim, Germany.

Bishop, C. D. 1995. Antiviral activity of the essential oil of Melaleuca alternifolia (Maiden and Betche) Cheel (tea tree) against tobacco mosaic virus. J. Essent. Oil Res. 7:641-644.

Burt, S. 2004. Essential oils: Their antibacterial properties and potential applications in foods-A review. Int. J. Food Microbiol. 94:223-253.

CLSI. 2009. Methods for Dilution Antimicrobial Susceptibility Tests for Bacteria That Grow Aerobically; Approved Standard. 8th ed. Clinical and Laboratory Standards Institute, Wayne, PA.

Coban, A. Y. 2012. Rapid determination of methicillin resistance among Staphylococcus aureus clinical isolates by colorimetric methods. J. Clin. Microbiol. 50:2191-2193.

Cox, S. D., C. M. Mann, J. L. Markham, H. C. Bell, J. E. Gustafson, J. R. Warmington, and S. G. Wyllie. 2000. The mode of antimicrobial action of the essential oil of Melaleuca alternifolia (tea tree oil). J. Appl. Microbiol. 88:170-175.

Cucarella, C., C. Colano, J. Valle, B. Amorena, I. Lasa, and P. Penades. 2001. Bap, a Staphylococcus aureus surface protein involved in biofilm formation. J. Bacteriol. 183:2888-2896.

Donlan, R. M., and J. W. Costerton. 2002. Biofilms: Survival mechanisms of clinically relevant microorganisms. Clin. Microbiol. Rev. 15:167-193.

Fonseca, P., and A. P. L. Librand. 2008. Evaluation of physico-chemical and phytochemical characteristics of differentt tientures of barbatimão (Stryphnodendron barbatimam). Braz. J. Pharm. Sci. 44:271-277.

Gao, M., M. Teplitski, J. B. Robinson, and W. D. Bauer. 2003. Production of substances by Medicago truncatula that affect bacterial quorum sensing. Mol. Plant Microbe Interact. 16:827-834.
Gibson, H., J. H. Taylor, K. E. Hall, and J. T. Holah. 1999. Effectiveness of cleaning techniques used in the food industry in terms of the removal of bacterial biofilms. J. Appl. Microbiol. 87:41-48.

Kim, Y. G., J. H. Lee, S. I. Kim, K. H. Baek, and J. Lee. 2015. Cinnamon bark oil and its components inhibit biofilm formation and toxin production. Int. J. Food Microbiol. 195:30-39.

Knowles, J. R., S. Roller, D. B. Murray, and A. S. Naidu. 2005. Antimicrobial action of carvacrol at different stages of dual-species biofilm development by Staphylococcus aureus and Salmonella enterica serovar Typhimurium. Appl. Environ. Microbiol. 71:797-803.

Koneman, E. W., S. D. Allen, W. M. Janda, P. C. Schreckenberger, and W. C. Winn Jr. 2008. Diagnostico Microbiológico-Texto e Atlas Colorido. 6th ed. Editora Guanabara Koogan, Rio de Janeiro, Brazil.

Kwiecinski, J., S. Eickb, and K. Wojcika. 2009. Effects of tea tree (Melaleuca alternifolia) oil on Staphylococcus aureus in biofilms and stationary growth phase. Int. J. Antimicrob. Agents 33:343-347.

Lasa, I., and J. R. Penades. 2006. Bap: A family of surface proteins involved in biofilm formation. Res. Microbiol. 157:99-107.

Li, W., H. Chen, Z. He, C. Han, S. Liu, and Y. Li. 2015. Influence of surfactant and oil composition on the stability and antibacterial activity of eugenol nanoemulsions. LWT Food Sci. Technol. (Campinas) 62:39-47.

Mari, M., P. Bertolini, and G. C. Pratella. 2003. Non-conventional methods for the control of post-harvest pear diseases. J. Appl. Microbiol. 94:761-766.

McKenney, D., J. Hübner, E. Muller, Y. Wang, D. A. Goldmann, and G. B. Pier. 1998. The ica locus of Staphylococcus epidermidis encodes production of the capsular polysaccharide/adhesin. Infect. Immun. 66:4711-4720.

Melchior, M. B., H. Vaarkamp, and J. Fink-Gremmels. 2006. Biofilms: A role in recurrent mastitis infections? Vet. J. 171:398-407.

Nostro, A., R. A. Sudano, G. Bisignano, A. Marino, M. A. Cannatelli, and F. C. Pizzimenti. 2007. Effects of oregano, carvacrol and thymol on Staphylococcus aureus and Staphylococcus epidermidis biofilms. J. Med. Microbiol. 56:519-523.

Ogunlana, E. O., S. Hoeglund, G. Onawunmi, and O. Skoeld. 1987. Effects of lemongrass oil on the morphological characteristics and peptidoglycan synthesis of Escherichia coli cells. Microbios 50:4359.

Saviuc, C. M., V. Drumea, L. Olariu, M. C. Chifiriuc, E. Bezirtzoglou, and V. Lazăr. 2015. Essential oils with microbicidal and antibiofilm activity. Curr. Pharm. Biotechnol. 16:137-151.

Seixas, R., J. P. Santos, R. Bexiga, L. C. Vilela, and M. Oliveira. 2014. Antimicrobial resistance and virulence characterization of methicillin-resistant staphylococci isolates from bovine mastitis cases in Portugal. J. Dairy Sci. 97:340-344.

Seo, Y. S., D. Y. Lee, N. Rayamahji, M. L. Kang, and H. S. Yoo. 2008. Biofilm-forming associated genotypic and phenotypic characteristics of Staphylococcus spp. isolated from animals and air. Res. Vet. Sci. 85:433-438.

Shen, S., T. Zhang, Y. Yuan, S. Lin, J. Xu, and H. Ye. 2015. Effects of cinnamaldehyde on Escherichia coli and Staphylococcus aureus membrane. Food Contr. 47:196-202.

Soni, K. A., A. Oladunjoye, R. Nannapaneni, M. W. Schilling, J. L. Silva, and B. Mikel. 2013. Inhibition and inactivation of Salmonella Typhimurium biofilms from polystyrene and stainless steel surfaces by essential oils and phenolic constituent carvacrol. J. Food Prot. 76:205-212.

Unlu, M., E. Ergene, G. V. Unlu, H. S. Zeytinoglu, and N. Vural. 2010. Composition, antimicrobial activity and in vitro cytotoxicity of essential oil from Cinnamomum zeylanicum Blume (Lauraceae). Food Chem. Toxicol. 48:3274-3280.

Vasudevan, P., M. K. M. Nair, T. Annamalai, and K. S. Venkitanarayanan. 2003. Phenotypic and genotypic characterization of bovine mastitis isolates of Staphylococcus aureus for biofilm formation. Vet. Microbiol. 92:179-185.

Vautor, E., G. Abadie, A. Pont, and R. Thiery. 2008. Evaluation of the presence of the bap gene in Staphylococcus aureus isolates recovered from human and animals species. Vet. Microbiol. 127:407-411. 